\title{
Preliminary results of highly localized plantar irradiation with low incident levels of mid-infrared energy which contributes to the prevention of dementia associated with underlying diabetes mellitus
}

\author{
Kenji Ryotokuji ${ }^{1}$, Keisou Ishimaru ${ }^{1}$, Kazuhiko Kihara ${ }^{1}$, \\ Takuma Nakajima ${ }^{1}$, Satoru Otani ${ }^{1}$, Yoshihisa Namiki ${ }^{1}$ \\ 1: Stress-free Therapy Research Center, Ryotokuji University
}

\begin{abstract}
Background and aims: The incidence of vascular dementia (VD) and Alzheimer's disease (AD) has recently increased and the prevention of progression of these diseases is very difficult.

Results: The application of pinpoint plantar long-wavelength infrared light irradiation (PP-LILI) to a patient's sole, at the point where the line drawn between the first and second metatarsal heads intersects with the vertical line from the medial malleolus, was effective in increasing blood flow to the facial artery, elevating high-density lipoprotein cholesterol (HDL-C) levels, and reducing insulin resistance.

Conclusions: We found that these effects of PP-LILI might be helpful for preventing VD and AD, conditions that are becoming a social problem in an aging Japanese society.
\end{abstract}

\section{Introduction}

In recent years, increasing attention has been paid to the co-morbidity of diabetes mellitus and dementia, diseases whose morbidity increases with age. In particular, it has been reported that the incidences of vascular dementia (VD) and Alzheimer's disease (AD), known as major causes of dementia, are higher in patients suffering from diabetes. ${ }^{1-8)}$

We have established Stress-free Therapy ${ }^{\circledR}$ (SF Therapy: Trademark Registration No. 5495960; Patent Application No. PCT [Patent Cooperation Treaty]/JP [Japan] 2012/073972), a drug-free therapy aimed at improving diabetes in an attempt to prevent dementia. This therapy elevates the patient's peripheral deep body temperature, increases blood flow, stabilizes blood pressure, and significantly decreases stress hormone levels (e.g., adrenocorticotropic hormone [ACTH] and cortisol). In pinpoint plantar low-wavelength infrared light irradiation (PP-LILI), low incident levels

Addressee for Correspondence:

Kenji Ryotokuji

Faculty of Health Sciences, Ryotokuji University

5-8-1 Akemi, Urayasu city, Chiba 279-8567, Japan.

TEL: +81-47-382-2111, FAX: +81-47-382-2017.

E-mail: honbu@ryotokuji.ac.jp of light energy are applied to the patient's sole in a pin-point manner, at the point where the line drawn between the first and second metatarsal heads intersects with the vertical line from the medial malleolus. ${ }^{1)}$ We previously reported that PP-LILI was useful for the treatment of early dementia, as it increased blood flow to the head and had significant beneficial effects on glycemic control and insulin resistance in patients with type 2 diabetes. ${ }^{2), 9-12)}$ In the present study, we examined whether PP-LILI could change blood flow to the facial artery and influence blood glucose, total cholesterol (TC), high-density lipoprotein cholesterol (HDLC), low-density lipoprotein cholesterol (LDL-C), and stress hormone (ACTH and glucocorticoid [cortisol]) levels in patients with type 2 diabetes.

\section{Methods}

PP-LILI was performed in 15 patients with type 2 dia-

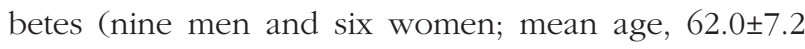
years) in whom glycemic control was difficult to achieve with medications.

After the patients rested in the supine position for

Received date: October 20th, 2014

Accepted date: February 18th, 2015 
15 minutes, PP-LILI was bilaterally applied to the sole at the point where the line drawn between the first and second metatarsal heads intersected with the vertical line from the medial malleolus for 15 minutes using the PP-LILI device (Controlled Medical Device Approval No. 224AFBZX00075000: highly localized probe $20 \mathrm{~mm}$ in diameter, mid infrared wavelength 9000-12000 nm, output $9.55 \mathrm{~mW}$ ). Blood flow in the facial artery was measured before and after irradiation to determine changes (Fig. 1). PP-LILI was applied once a week four times on average. During the course of the therapy, oral diabetes medications were continued.

Blood samples (3 cc) were collected from the cubital vein before and after PP-LILI and immediately centrifuged (1200 G for 5 minutes) to analyze blood glucose, hemoglobin A1c, HDL-C, LDL-C, and stress hormone (ACTH and cortisol) levels. ACTH was quantified by a chemiluminescence immunoassay; cortisol, by an electrochemiluminescence immunoassay; and blood glucose, by the enzymatic method. To ensure consistency, blood samples were collected at the same time of the day in consideration of the impact of measurement time and circadian rhythm on test values.

Changes in blood flow to the facial artery were assessed using a laser Doppler flow meter (Advance ALF21) that quantified blood flow in the facial artery (one of the branches of the total carotid artery that carries blood to the brain) for 15 minutes each - once during the resting period, and a second time after completion of PP-LILI.

\section{Ethical consideration}

This study was conducted after review and approval (2304) by the Ethics Committee of Ryotokuji University. Written informed consent was obtained from each patient after a full explanation of the nature and aims of the study.

Statistical evaluation of the data was performed using the sign test and paired t-test, with p-values of less than 0.05 considered to be significant.

\section{Results}

\section{Changes in Blood Glucose, Insulin, TC, HDL-C, and LDL-C Levels}

PP-LILI led to a significant decrease in blood glucose levels from $173.5 \pm 57.0 \mathrm{mg} / \mathrm{dl}$ before therapy to $132.4 \pm 42.4 \mathrm{mg} / \mathrm{dl}$ after therapy $(\mathrm{P}<0.01 ;$ Fig. 2). Moreover, insulin and TC levels also showed a significant decrease: insulin levels decreased from $15.3 \pm 11.8$ $\mu \mathrm{U} / \mathrm{dl}$ to $10.7 \pm 7.9 \mu \mathrm{U} / \mathrm{dl}(\mathrm{P}<0.05$; Fig. 3), and TC levels decreased from $214.5 \pm 48.1 \mathrm{mg} / \mathrm{dl}$ to $198.0 \pm 55.7 \mathrm{mg} / \mathrm{dl}$ $(\mathrm{P}<0.01$; Fig. 4). HDL-C levels decreased from $51.9 \pm 9.5$ $\mathrm{mg} / \mathrm{dl}$ to $49.4 \pm 9.8 \mathrm{mg} / \mathrm{dl}$, but the decrease was not statistically significant (Fig. 5). On the other hand, LDL-C levels significantly increased from $119.7 \pm 34.9 \mathrm{mg} / \mathrm{dl}$ before therapy to $129.4 \pm 37.9 \mathrm{mg} / \mathrm{dl}$ after therapy (P $<0.05$; Fig. 6). Thus, such a decrease in LDL-C levels, unlike HDL-C levels, was proportional to a significant
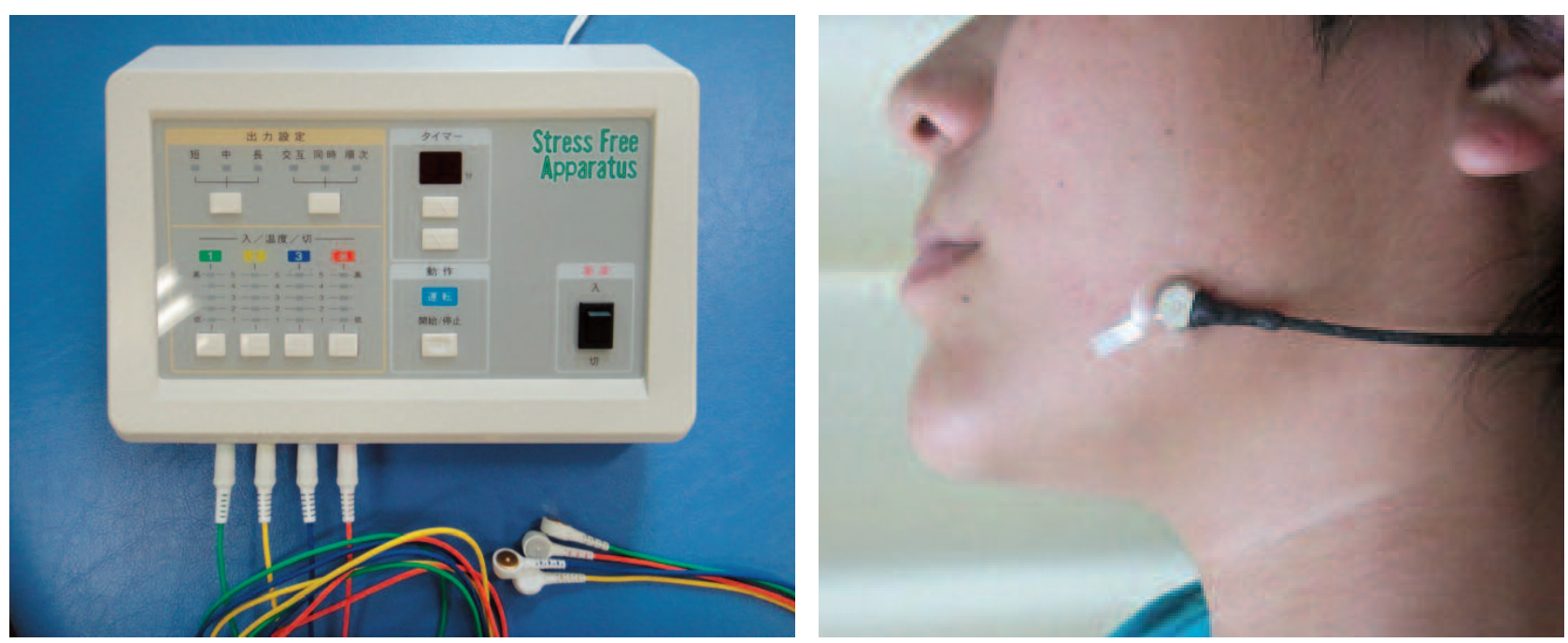

Fig. 1: Stress-free Therapy ${ }^{\circledR}$ device (Controlled Medical Device Approval No. 224AFBZX00075000: probe $20 \mathrm{~mm}$ in diameter, far infrared wavelength $9000-12000 \mathrm{~nm}$, output $9.55 \mathrm{~mW}$ ) (left) and the measurement portion of the blood flow (right). The facial artery is a branch of the total carotid artery which supplies blood to the brain. 
decrease in blood glucose, insulin, and TC levels.

\section{Changes in Stress Hormone (Cortisol and ACTH) Levels}

Both cortisol and ACTH levels were significantly lower after PP-LILI than before therapy. Cortisol levels decreased from $10.7 \pm 5.4 \mu \mathrm{g} / \mathrm{dl}$ to $8.0 \pm 3.7 \mu \mathrm{g} / \mathrm{dl}$ $(\mathrm{P}<0.01$; Fig. 7), and ACTH levels decreased from $20.5 \pm 11.4 \mathrm{pg} / \mathrm{ml}$ to $14.6 \pm 7.4 \mathrm{pg} / \mathrm{ml}(\mathrm{P}<0.05$; Fig. 8).

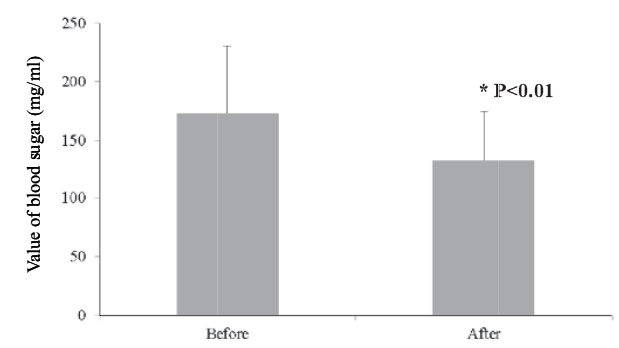

Figure 2: Changes in Blood Glucose

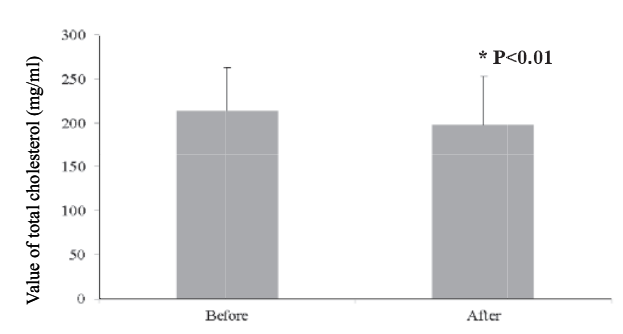

Figure 4: Changes in Total Cholesterol

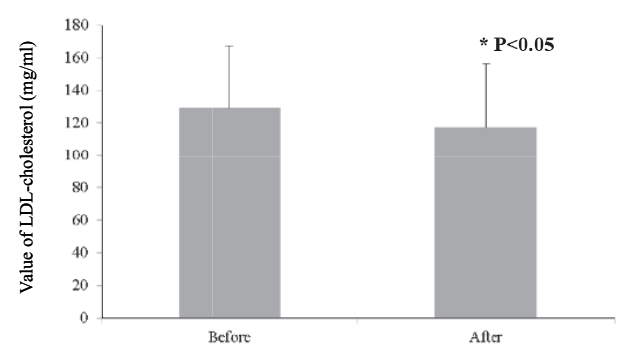

Figure 6: Changes in LDL Cholesterol

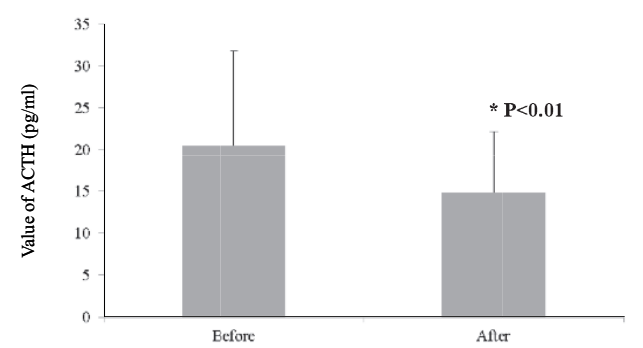

Figure 8: Changes in ACTH

\section{Changes in Blood Flow to the Facial artery}

The mean blood flow to the facial artery significantly increased from $3.0 \pm 2.1 \mathrm{ml} / \mathrm{min} / 100 \mathrm{~g}$ tissue before PPLILI to $8.1 \pm 4.7 \mathrm{ml} / \mathrm{min} / 100 \mathrm{~g}$ tissue after PP-LILI (both measured for 15 minutes) ( $\mathrm{P}<0.001$; Fig. 9). As shown in Table 1, 7 cases (case No.: 3, 4, 8, 11, 12, 13, 14) displayed the 3 -fold increases of blood flow after PPLILI.

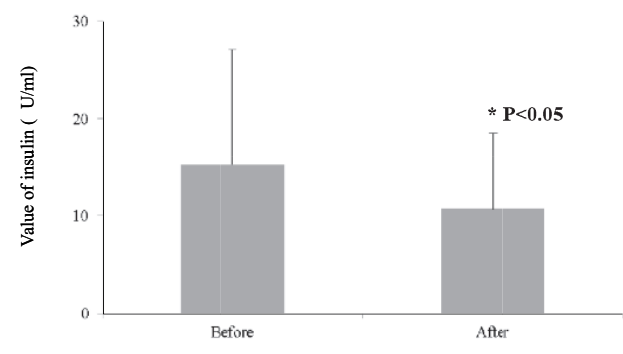

Figure 3: Changes in Insulin

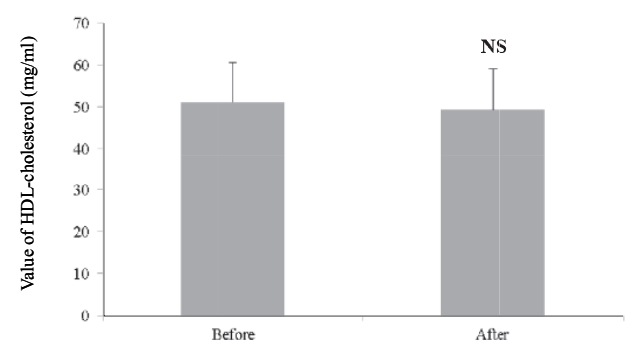

Figure 5: Changes in HDL Cholesterol

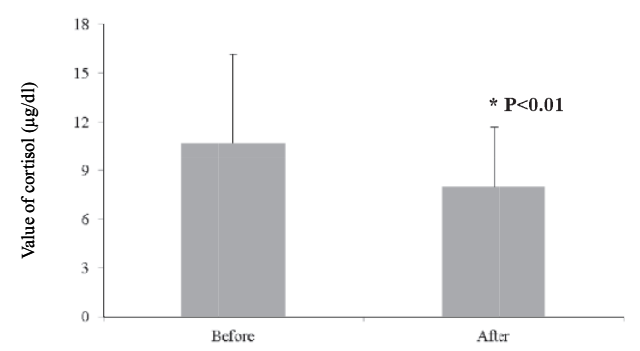

Figure 7: Changes in Cortisol

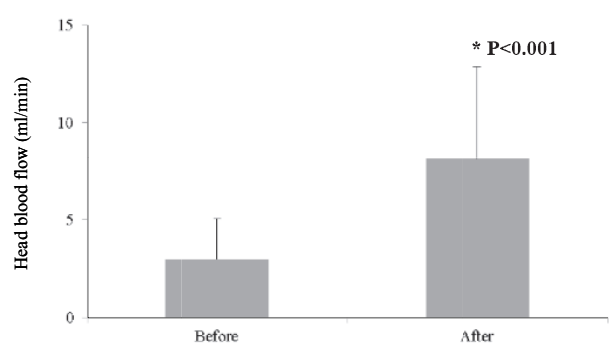

Figure 9: Changes in blood flow to the facial artery 
Table 1: The changes in blood flow of the facial artery

\begin{tabular}{|c|c|c|c|c|}
\hline Case & Sex & Age & $\begin{array}{c}\text { Blood flow } \\
(\mathrm{ml} / \mathrm{min} / 100 \mathrm{~g} \text { tissue; before the treatment })\end{array}$ & $\begin{array}{c}\text { Blood flow } \\
\text { (ml/min/100g tissue; after the treatment) }\end{array}$ \\
\hline 1 & Female & 64 & 1.8382 & 4.8927 \\
\hline 2 & Female & 60 & 2.2788 & 6.0511 \\
\hline 3 & Male & 69 & 1.4403 & 5.0540 \\
\hline 4 & Male & 62 & 1.6554 & 5.1752 \\
\hline 5 & Male & 74 & 2.4357 & 5.3784 \\
\hline 6 & Male & 66 & 3.4252 & 7.4445 \\
\hline 7 & Female & 66 & 2.6650 & 7.7034 \\
\hline 8 & Female & 50 & 2.1269 & 6.9604 \\
\hline 9 & Male & 54 & 3.4819 & 9.3156 \\
\hline 10 & Male & 47 & 4.2082 & 7.8473 \\
\hline 11 & Male & 61 & 2.8971 & 9.7831 \\
\hline 12 & Male & 68 & 1.1030 & 4.7177 \\
\hline 13 & Male & 62 & 3.1497 & 9.6122 \\
\hline 14 & Female & 67 & 2.1148 & 7.9232 \\
\hline \multirow[t]{3}{*}{15} & Female & 60 & 9.9197 & 24.030 \\
\hline & AVE & 62.0 & 3.0 & 8.1 \\
\hline & SD & 7.2 & 2.1 & 4.7 \\
\hline
\end{tabular}

\section{Discussion}

Recent epidemiological and clinical studies have shown that the incidences of co-morbid vascular dementia and Alzheimer's disease are higher among patients with diabetes compared with non-diabetic population. ${ }^{6-8)}$ The following mechanism for this comorbidity has been proposed: insulin resistance and hyperinsulinemia, which are observed in metabolic syndrome and diabetes mellitus, evoke a low-insulin state in the central nervous system that consequently causes decreased cerebral blood flow and accumulation of amyloid in the brain, ultimately leading to a development of AD. 9) Insulin also regulates glucose and energy metabolism in the brain. In hyperglycemia, the decreased transport of insulin to the brain causes decreased insulin action, attenuating the neuroprotective effects of insulin. Importantly, insulin receptors are densely localized in the hypothalamus and the hippocampus, important areas for memory. ${ }^{13}$ )

We have previously reported that PP-LILI significantly decreases stress markers (ACTH and cortisol) released from the hypothalamus, significantly improves insulin resistance in type 2 diabetes, and increases blood flow in the facial artery. ${ }^{9-12)}$ A novel finding of this study is that PP-LILI in patients with type 2 diabetes helped increase blood flow to the facial artery, thereby normalizing insulin resistance and metabolism (i.e., blood glucose levels). The facial artery is a branch of the total carotid artery which supplies blood to the brain. In healthy adults, the blood flow in the facial artery is usually regulated at the level around 7 to 11 $\left.\mathrm{ml} / \mathrm{min} .{ }^{14}, 15\right)$ We would like to put special emphasis on the concept that the average flow in the patients in the present study was outside of the normal range $(3.0 \pm 2.1 \mathrm{ml} / \mathrm{min})$ before the treatment but it improved to be within the normal range $(8.1 \pm 4.7 \mathrm{ml} / \mathrm{min} / 100 \mathrm{~g}$ tissue) after the treatment.

This may contribute to the prevention of dementia (e.g., VD and AD) associated with diabetes mellitus. Specifically, we suggest that decreased ACTH and cortisol levels (stress markers released from the adrenal cortex) and increased blood flow may help enhance neural activity and prevent accumulation of $\beta$ amyloid 
in the brain.

In regard to wavelength of the light, we have chosen mid-infrared wavelength incident light because water easily adsorbs such light, moreover we have irradiated bilaterally to enforce the therapeutic effect.

In the elderly, high HDL-C levels have been reported to be effective not only in reducing the risk of developing $\mathrm{AD}$, but also for preventing cognitive decline and the development of VD. ${ }^{16-19)}$ In our present study, LDL-C levels, along with blood glucose and insulin levels, were significantly decreased, though HDL-C levels remained unchanged. This indicates that PP-LILI could be effective for preventing dementia.

Administration of insulin, combined with an adequate amount of glucose, enhances memory and inhibits the accumulation of $\beta$ amyloid in brain cells in both healthy persons and patients with AD. ${ }^{16)}$ We pre-

\section{References}

1: Yang HT, Sheen YJ, Kao CD, et al (2013). Association between the characteristics of metabolic syndrome and Alzheimer's disease. Metab Brain Dis. 28(4):597-604.

2: Fukazawa R, Hanyu H, Sato T, et al. (2013). Subgroups of Alzheimer's disease associated with diabetes mellitus based on brain imaging. Dement Geriatr Cogn Disord. 35(5-6):280-290.

3: Exalto LG, Whitmer RA, Kappele LJ, et al. (2012). An update on type 2 diabetes, vascular dementia and Alzheimer's disease. Exp Gerontol. 47(11):858864 .

4: Bosco D, Fava A, Plastino M, (2011). Possible implications of insulin resistance and glucose metabolism in Alzheimer's disease pathogenesis. J Cell Mol Med. 15(9):1807-1821.

5: Sato N, Takeda S, Uchio-Yamada K, (2011). Role of insulin signaling in the interaction between Alzheimer disease and diabetes mellitus: a missing link to therapeutic potential. Curr Aging Sci. 4(2):118-127.

6: Kopf D, Frolich L (2009). Risk of incident Alzheimer's disease in diabetic patients: A systemic review of prospective trials. J Alzheimer Dis. 16: 677-685.

7: Vignini A, Giulietti A, Nanetti L et al (2013). Alzheimer's disease and diabetes: new insights and unifying therapies. Curr Diabetes Rev. 9(3):218227.

8: Exalto LG, Whitmer RA, Kappele LJ, Biessels GJ (2012). Diabetes mellitus and the risk of viously reported that memory is also improved following PP-LILI. 12) Taken together, these results suggest that PP-LILI might be helpful for preventing the development of $\mathrm{VD}$ and $\mathrm{AD}$, known as the causes of dementia, by normalizing insulin activity in the brain, increasing blood flow to the facial artery, and enhancing neural activity in the hippocampus and other areas to improve memory.

\section{Conclusion}

Our study revealed that PP-LILI significantly increased blood flow to the facial artery and normalized insulin and stress hormone metabolism. Our findings may help to develop new therapeutic strategies that could prevent the development of VD and AD.

Alzheimer's disease: a nationwide populationbased study. Exp Gerontol. 47(11):858-864.

9: Ryotokuji K, Ishimaru K, Kihara K, et al (2013). Effect of Pinpoint Plantar Long-wavelength Infrared Light Irradiation on Subcutaneous Temperature and Stress Markers. Laser Therapy. 22 (2) 93-102.

10: Ryotokuji K, Ishimaru K, Kihara K, et al (2013). Preliminary Results of Pinpoint Plantar Long-wavelength Infrared Light Irradiation on Blood Glucose, Insulin and Stress Hormones in Patients with Type 2 Diabetes Mellitus. Laser Therapy. 22 (3) 209-214.

11: Ryotokuji K, Ishimaru K, Kihara K, et al (2014). Preliminary Results of Stress-free Therapy on Cerebral Blood Flow: Comparisons Among Patients with Metabolic Cardiovascular Disease, Healthy Subjects and Placebo-treated Subjects. Laser Therapy. 23(1) 9-12.

12: Ryotokuji K, Ishimaru K, Kihara K, et al (2014). Stress-free therapy ${ }^{\circledR}$ in a patient with impaired early stage of dementia Improvement of head blood stream and increment of osteopontin gene expression. The Journal of Japan Society for Early Stage of Dementia. 7 (1) 113-116.

13: Ott A, Stolk RP, van Harskamp F, Pols HA et al (1999). Diabetes mellitus and the risk of dementia. Neurology. 53: 1937-1942.

14: Utsunomiya M, Ohura H, Takiwaki H, et al (1990). Measurement of skin blood flow by the laser doppler flowmetry. Nishi Nihon Hifuka. 52 (6): 1164-1171.

15: Nakanishi Y, Goto M, Ishikawa K, Katsuki T 
(1992). Microcirculatory measurements of normal maxilla-facial tissue by laser Doppler flowmeter. Japan Society for Laser Density. 3: 29-34.

16: Reitz C, Tanq MX, Schupf N, et al (2010). Association of higher levels of high-density lipoprotein cholesterol in elderly individuals and lower risk of late-onset Alzheimer's disease. Arch Neurol. 67: 1491-1497.

17: Yaffe K, Barrett-Connor E, Lin F, at al (2002).
Serum lipoprotein levels, statin use, and cognitive function in older women. Arch Neurol. 59; 378384.

18: Moroney JT, Tang MX, Berglund L, et al (1999). Low-density lipoprotein cholesterol and the risk of dementia with stroke. JAMA. 282: 254-260.

19: Schwarzt MW, Porte D Jr (2005). Diabetes, obesity, and the brain. Science. 307: 375-379. 